\title{
Leaders
}

\section{Investigation of CMV disease in immunocompromised patients}

\author{
V C Emery
}

\begin{abstract}
Cytomegalovirus (CMV) is a recognised cause of morbidity and mortality in immunocompromised individuals. This review will concentrate on recent advances in the understanding of the complex interplay between the host and parasite and the pathological consequences of perturbation of the host immune system. The classic view of $\mathrm{CMV}$ as a slowly replicating virus is challenged by recent in vivo findings suggesting that active replication occurs dynamically in the human host, with a doubling time of approximately one day. In addition, CMV load plays a major role in viral pathogenesis, such that increased CMV replication is a significant risk factor for disease in all immunocompromised groups studied to date. These studies focus attention on understanding the virological and immunological determinants of enhanced viral replication and its pathological consequences.

(f Clin Pathol 2001;54:84-88)
\end{abstract}

Keywords: polymerase chain reaction; quantitation; inclusion bodies; antiviral chemotherapy

Accepted for publication

13 December 1999

Table 1 Key genes encoded by cytomegalovirus (CMV). The list merely highlights genes that are either discussed in the text or are pertinent to viral pathogenicity and does not aim to be exhaustive

\begin{tabular}{|c|c|}
\hline Gene & Function \\
\hline UL55 (glycoprotein B) & $\begin{array}{l}\text { Surface glycoprotein and major target for neutralising } \\
\text { antibodies }\end{array}$ \\
\hline UL83 (pp65) & $\begin{array}{l}\text { Major target for CD8 restricted cytotoxic lymphocytes. } \\
\text { Major virion structural protein }\end{array}$ \\
\hline US27, US28, UL33, UL75 & $\begin{array}{l}\mathrm{G} \text { coupled receptor family members. US } 28 \text { acts as a } \\
\text { promiscuous chemokine receptor. }\end{array}$ \\
\hline US2, US3, US6 and US11 & $\begin{array}{l}\text { Proteins involved in the downregulation of HLA class I } \\
\text { display on infected cells }\end{array}$ \\
\hline UL18 & $\begin{array}{l}\text { Class I HLA homologue. } \\
\text { Binds } \beta_{2} \text {-microglobulin and may function as an NK } \\
\text { decoy }\end{array}$ \\
\hline UL146 & $\begin{array}{l}\text { CXC chemokine homologue able to chemoattract } \\
\text { neutrophils }\end{array}$ \\
\hline $\begin{array}{l}\text { UL112/113 (immediate-early genes } \\
\text { IE1/IE2) }\end{array}$ & $\begin{array}{l}\text { Key transactivators required for the replication of } \\
\text { CMV. } \\
\text { Able to interfere with the cell cycle }\end{array}$ \\
\hline UL80A & $\begin{array}{l}\text { Protease encoded by all herpesviruses and necessary } \\
\text { for capsid assembly }\end{array}$ \\
\hline UL97 & $\begin{array}{l}\text { Protein kinase essential for replication. } \\
\text { Activates ganciclovir to its monophosphate. } \\
\text { Site of action of the benzimidazole classes of drugs }\end{array}$ \\
\hline UL54 & $\begin{array}{l}\text { DNA polymerase. Site of action of antiviral } \\
\text { compounds such as ganciclovir (triphosphate), } \\
\text { aciclovir (triphosphate), cidofovir (disphosphate), } \\
\text { and foscarnet }\end{array}$ \\
\hline
\end{tabular}

HLA, human major histocompatibility complex; NK, natural killer cell.
Cytomegalovirus (CMV) is the prototype member of the Betaherpesvirinae. As with all members of the Herpesviridae, the virus has the ability to persist in the host in a latent state after primary infection. In the immunocompetent individual, the virus and host exist in a symbiotic equilibrium, such that disease manifestations are rarely encountered. ${ }^{1}$ However, when the host immune system is compromised, either through infection-for example, by human immunodeficiency virus (HIV), immaturity (neonate), or through iatrogenic means following organ transplantation, the virus is able to exert its full pathogenic potential. ${ }^{12}$ In this review, I will summarise key features of the genetics and immunology of CMV pertinent to understanding its pathogenicity, and show how viral load measures for CMV have facilitated our understanding of CMV pathology and the dynamics of virus replication in vivo.

\section{Genetics and replication of CMV}

The entire DNA sequence of a prototype laboratory strain, Ad169, has been available since $1990 .^{3}$ The genome comprises $229354 \mathrm{bp}$ and has the capacity to encode in excess of 200 genes. However, it has become clear in recent years that this highly passaged virus might not be truly representative of clinical strains of CMV, and a recent study has shown that low passage pathogenic laboratory strains of CMV (Towne and Toledo) have up to $20 \mathrm{kbp}$ of additional DNA within the genome. ${ }^{4}$ Most of the genes in this region are unique but have structural motifs reminiscent of cellular proteins-for example, CXC motifs and RGD motifs. Thus, at present, CMV appears to contain the largest genome of any virus infecting humans. Multiple strains of virus circulate both within the population and within an individual, and evidence exists for interstrain recombination..$^{5-7}$ These factors contribute to the diversity of CMV within the population. Table 1 shows a list of key genes encoded by CMV, grouped according to their known or predicted functions.

CMV replication in vitro is relatively slow and frequently cultures of clinical specimens need to be maintained for many weeks before characteristic cytopathic effects are observed. However, until recently, the relevance of these observations to the replication of CMV in vivo was unclear. The most common cell type for the propagation of CMV in vitro is the primary 


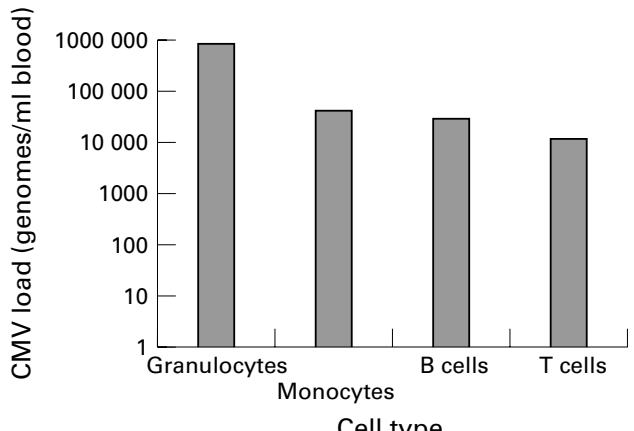

Figure 1 Distribution of cytomegalovirus (CMV) load in cell types present in the blood (granulocytes/neutrophils, monocytes, $B$ cells, and $T$ cells) during an active CMV infection of a renal transplant recipient. Cell subsets were purified using Dynabeads coated with the appropriate antibody and a combination of positive and negative selection according to the recommendations of the manufacturer.

fibroblast; a cell type that is not predominantly infected in vivo. In latent infections, CD14 positive monocytes have been shown to be a major reservoir of virus, and prolonged allogeneic stimulation of these cells from healthy seropositive people can lead to the reactivation of virus. ${ }^{8}$ In contrast, during an active infection, multiple cell types are infected, although the predominant cell types appear to be endothelial cells, neutrophils, and lymphocytes (fig 1). To determine the replication rate of CMV in vivo, we have used a similar approach to that used to study the dynamics of HIV,${ }^{9}{ }^{10}$ hepatitis $\mathrm{B}$ virus (HBV), ${ }^{11}$ and hepatitis $\mathrm{C}$ virus $(\mathrm{HCV})^{12}$ replication through the frequent measurement of CMV load in blood following antiviral intervention. ${ }^{13}$ These data demonstrate that, during an active CMV infection, the doubling time of $\mathrm{CMV}$ is approximately one day; thus, CMV replication occurs dynamically in the human host, and so contrasts with the results obtained from in vitro propagation. ${ }^{13}$ The implications of these data for the monitoring and treatment of CMV infection will be discussed later.

\section{The immune system and CMV}

Because most immunocompetent individuals do not suffer from CMV disease during either primary or recurrent infections, the immune system must be effective in controlling replication. However, this simplistic assumption masks a level of complexity between the virus and host that is still being unravelled. The $\mathrm{B}$ cell response to $\mathrm{CMV}$ is largely dominated by an anti-glycoprotein B cell response, and most of the neutralising antibodies are also directed against this protein. ${ }^{14}{ }^{15}$ In contrast, the cytotoxic $\mathrm{T}$ cell (CD8) response is almost exclusively directed against the pp65 (UL83) protein and epitopes have been mapped for human major histocompatibility complex (HLA) types $A^{\star} 0201, B^{\star} 0701, B^{\star} 0801$, and $\mathrm{B} \star 3501$ (table 1). ${ }^{16}{ }^{17}$ The frequency of cytotoxic $\mathrm{T}$ lymphocytes (CTLs) against CMV in immunocompetent individuals has been estimated to be $1 / 5000$ by classic endpoint dilution chromium release assays but, using more recently developed HLA class I tetramer technology, this frequency may be much higher. ${ }^{18-20}$
In the face of such an aggressive immune response, how does the virus survive? It is now clear that CMV encodes a range of gene products and uses several mechanisms to manipulate the host immune system. ${ }^{21}$ Thus, the presentation of immediate-early antigens is suppressed by phosphorylation by a virion phosphoprotein, which leads to a lack of processing within the proteasome $\mathrm{e}^{22}$; in addition, the HLA class I display pathway is interrupted at multiple time points after infection via interaction with the TAP system, the recycling system, and terminal maturation by genes US2, US3, US6, and US11. ${ }^{21}$ The consequences of reduced HLA class I display should result in an increased susceptibility to natural killer (NK) cell activity, because cells require presentation of the signal peptides derived from HLA class I A, B, or C to be protected against $\mathrm{NK}$ cell lysis. ${ }^{23}$ However, the CMV genome contains an HLA class I homologue (UL18), which is synthesised late in the viral replicative cycle, when HLA class I downregulation is maximal ${ }^{24}$; UL18 forms complexes with $\beta_{2}$-microglobulin and traffics to the cell surface. ${ }^{25} 26$ The precise function of this protein remains controversial but in one study it could protect cells against $\mathrm{NK}$ lysis $^{27}$ to maintain immune evasion. In addition to encoding HLA class I dysregulatory genes, the genome encodes four potential G coupled protein receptors, one of which (US28) acts as a broad specificity $\beta$ chemokine receptor and can act as a coreceptor for the uptake of HIV. ${ }^{28}{ }^{29}$ The genome also contains two genes with homology to the CXC chemokine family, ${ }^{4}$ and one of these has been shown to stimulate neutrophil migration with the same potency as other cellular chemokines. ${ }^{30}$ It is likely that all these genes and other uncharacterised viral products act in concert within the host to facilitate viral and host survival. Perturbations of this dynamic equilibrium will result in a shift in the balance in favour of the virus and will have pathological consequences.

\section{Pathological consequences of $\mathrm{CMV}$ infection}

The incidence of CMV disease in different patient groups is not uniform and in most groups has declined as more aggressive management strategies have been used-for example, early treatment of active infection or prophylactic treatment with antivirals. ${ }^{31}$ Nevertheless, CMV disease remains a substantial problem in many groups and, with the increased use of potent antiviral drugs, resistant strains are becoming evident. ${ }^{32}$ Table 2 summarises the different pathological manifestations observed in solid organ transplant recipients, bone marrow transplant recipients, and patients with AIDS. The predominant disease in patients with AIDS has been retinitis, but this disease is relatively infrequent in other patient groups. In contrast, CMV pneumonitis is a major disease in bone marrow transplant recipients, whereas its incidence is much lower in solid organ transplant recipients. In liver transplant recipients, CMV hepatitis is frequently diagnosed, whereas this is not the case 
Table 2 Pathological manifestation of cytomegalovirus $(C M V)$ in different immunocompromised host

\begin{tabular}{llll}
\hline Symptoms & $\begin{array}{l}\text { Solid organ } \\
\text { recipients }\end{array}$ & $\begin{array}{l}\text { Bone } \\
\text { marrow } \\
\text { recipients }\end{array}$ & $\begin{array}{l}\text { AIDS } \\
\text { patients }\end{array}$ \\
\hline Fever & $\checkmark$ & $\checkmark$ & $\checkmark$ \\
Hepatitis & $\checkmark \checkmark$ & $\checkmark$ & $\checkmark$ \\
$\begin{array}{l}\text { Gastrointestinal } \\
\text { Retinitis }\end{array}$ & $\checkmark$ & $\checkmark$ & $\checkmark \checkmark$ \\
$\begin{array}{l}\text { Pneumonitis } \\
\text { Encephalopathy }\end{array}$ & $\checkmark$ & $\checkmark$ & $\checkmark$ \\
$\begin{array}{l}\text { Polyradiculopathy } \\
\text { Myelosuppression }\end{array}$ & & $\checkmark \checkmark$ & $\checkmark$ \\
Immunosuppression & $\checkmark$ & $\checkmark \checkmark$ & \\
$\begin{array}{l}\text { Rejection } \\
\text { Addisonian }\end{array}$ & $\checkmark$ & & \\
\hline
\end{tabular}

It should be noted that some of these manifestations do not reach the criteria for CMV disease outlined in table 3. The relative incidence is indicated by the number of symbols $(\checkmark)$.

in other groups. The underlying reasons for these differences are not known, but may reflect a combination of the proinflammatory cytokine cocktail generated following organ transplantation, together with the duration of replication. For example, in patients with AIDS and congenitally infected infants, CMV replication usually occurs at a persistently high level for many months, whereas most transplant recipients have an acute $\mathrm{CMV}$ infection, which subsequently results in disease in a relatively short time frame. In addition to viral replication directly causing pathology (for example, hepatitis), there is increasing evidence that the host's immune system might also contribute to the pathology observed. ${ }^{33}$ This has been suggested to account for the pathology of CMV pneumonitis, because it is only when patients are able to mount a sufficient immune response that the disease is observed. Thus, patients with AIDS who frequently harbour CMV in their lungs have a low incidence of CMV pneumonitis, ${ }^{34}$ whereas the disease has been observed in HIV positive individuals with high CD4+ cell numbers. ${ }^{35}$ The recent introduction of highly active antiretroviral therapy (HAART) for HIV infection has resulted in an inflammatory vitritis in patients with CMV retinitis which, in some cases, has resulted in the loss of vision. ${ }^{36}{ }^{37}$ Thus, paradoxically, the CMV replication accompanying sight threatening CMV retinitis can be controlled by the administration of HAART but the regeneration of specific immune responses causes a new pathology, which can be equally destructive to the host tissue and deleterious to the quality of life of the patient.

Table 3 Definitions of cytomegalovirus (CMV) disease ${ }^{38}$

\begin{tabular}{ll}
\hline Disease & Definition \\
\hline Pneumonia (transplant recipients) & $\begin{array}{l}\text { Radiographic changes and/or hypoxia. } \\
\text { CMV detected in BAL or lung biopsy }\end{array}$ \\
Pneumonia (HIV infected patients) & $\begin{array}{l}\text { Symptoms of pneumonia with hypoxaemia. } \\
\text { CMV detected in the lung. } \\
\text { Absence of other pathogens } \\
\text { Gastrointestinal symptoms with CMV detected by } \\
\text { histology } \\
\text { Abnormal liver function tests coupled with histological } \\
\text { changes and CMV detection in a liver biopsy by culture, } \\
\text { histology, or DNA hybridisation }\end{array}$ \\
Hepatitis & $\begin{array}{c}\text { Symptoms of encephalitis, transverse myelitis, or other } \\
\text { CNS symptoms, plus CMV in the CSF by culture or } \\
\text { PCR }\end{array}$ \\
Pypical ophthalmological lesions without virological proof
\end{tabular}

BAL, bronchial lavage fluid; CNS, central nervous system; CSF, cerebrospinal fluid.

\section{Diagnosis of CMV disease}

As mentioned above, CMV disease can take many forms, depending upon the type of patient group under consideration. A consensus is available from the international CMV workshop for the definition of CMV disease, and is summarised in table $3 .^{38}$ Thus, CMV hepatitis can only be proved if the virus is detected by histopathology in the liver biopsy, either by observation of CMV inclusion bodies or by immunohistochemical staining. On the other hand, CMV retinitis can be diagnosed by a qualified ophthalmologist in the absence of any virological evidence because this condition is usually self evident. The guidelines shown in table 3 are purposefully rigorous and have aided the interpretation of clinical trial data and population based studies. However, they are likely to lead to an under appreciation of the contribution of CMV to patient morbidity. This is particularly true in the case of the histopathological diagnosis of CMV. My group has correlated CMV load in tissues obtained at postmortem examination of patients with AIDS with the histological evidence of CMV inclusions and found that a viral load of $>5000000$ genomes/ $\mu \mathrm{g}$ DNA is required before CMV inclusions are observed. ${ }^{39}$ Therefore, it seems likely that some cases of CMV hepatitis may be dismissed because they do not reach the definition in table 3, despite the presence of abnormal liver function tests and CMV DNA in the blood. It is important to appreciate that, with the advent of more sensitive molecular based assays, a reappraisal of many of these definitions may be required.

\section{The role of CMV load in pathogenesis}

As the sensitivity and reproducibility of quantitative laboratory methods has improved, it has become increasingly evident that the viral load is a central factor in the pathogenesis of many viral infections. ${ }^{40}{ }^{41}$ In the case of CMV, the viral titre in the urine of congenitally infected infants (who excrete large amounts of virus at birth) was first shown to be associated with concurrent disease and the likelihood of developing disease in 1975. ${ }^{42}$ However, because most immunocompromised hosts have much lower amounts of virus circulating in the blood during an active infection, measurement using classic cell culture methods proved to be unsatisfactory. The advent of molecular methods circumvented these problems and data from a range of studies using DNA hybridisation and semiquantitative polymerase chain reaction (PCR) showed that symptomatic immunocompromised patients usually had significantly higher CMV loads than patients with active CMV infection who remained asymptomatic. ${ }^{43-45}$ My group has substantially extended these studies by using quantitative competitive PCR in longitudinal analyses of different patient groups at risk of CMV disease. ${ }^{46-53}$

In bone marrow transplant, renal transplant, and liver transplant recipients, peak CMV load is the major risk factor associated with CMV disease (table 4). Other established risk factors for CMV disease, such as donor/recipient serostatus, are entirely explained by raised CMV 
Table 4 Multivariate logistic regression analysis to determine the relative importance of cytomegalovirus (CMV) load as a risk factor for disease after organ transplantation

\begin{tabular}{|c|c|c|}
\hline Patient group & OR for $C M V$ disease $(95 \% C I)$ & $p$ Value \\
\hline \multicolumn{3}{|l|}{ Renal transplant recipients } \\
\hline CMV load & $1.65(1.14$ to 2.39$)$ & 0.008 \\
\hline \multicolumn{3}{|l|}{ Liver transplant recipients } \\
\hline CMV load & $2.70(1.41$ to 5.17$)$ & 0.003 \\
\hline Methylprednisolone $/ 1 \mathrm{~g}$ & $1.61(1.04$ to 2.51$)$ & 0.03 \\
\hline \multicolumn{3}{|l|}{ Bone marrow transplant recipients } \\
\hline CMV load & $1.43(1.12$ to 1.82$)$ & 0.004 \\
\hline
\end{tabular}

All ORs refer to an increase in CMV load of $0.25 \log _{10}$ genomes $/ \mathrm{ml}$ of blood.

In these analyses, raised viral load explained established risk factors for disease, such as donor/recipient serostatus and receipt of antithymocyte globulin (renal transplant patients), and these risk factors are therefore not recorded in the table.

The reader should consult the reference list for a comprehensive set of analyses. ${ }^{49-53}$ CI, confidence interval; OR odds ratio.

load. There is one exception to this; the receipt of methylprednisolone to control rejection episodes in liver transplant recipients continues to be a risk factor independent of raised CMV load in multivariate analyses. ${ }^{49}$ The explanation of this effect provides further insight into the delicate balance between the host and virus and the pathological process. Thus, each $3 \mathrm{~g}$ dose of methylprednisone acts to suppress the viral load needed to cause disease; that is, host susceptibility to disease is increased for a given viral load. This effect appears to be unique to methylprednisolone because the increased risk for disease associated with the receipt of antithymocyte
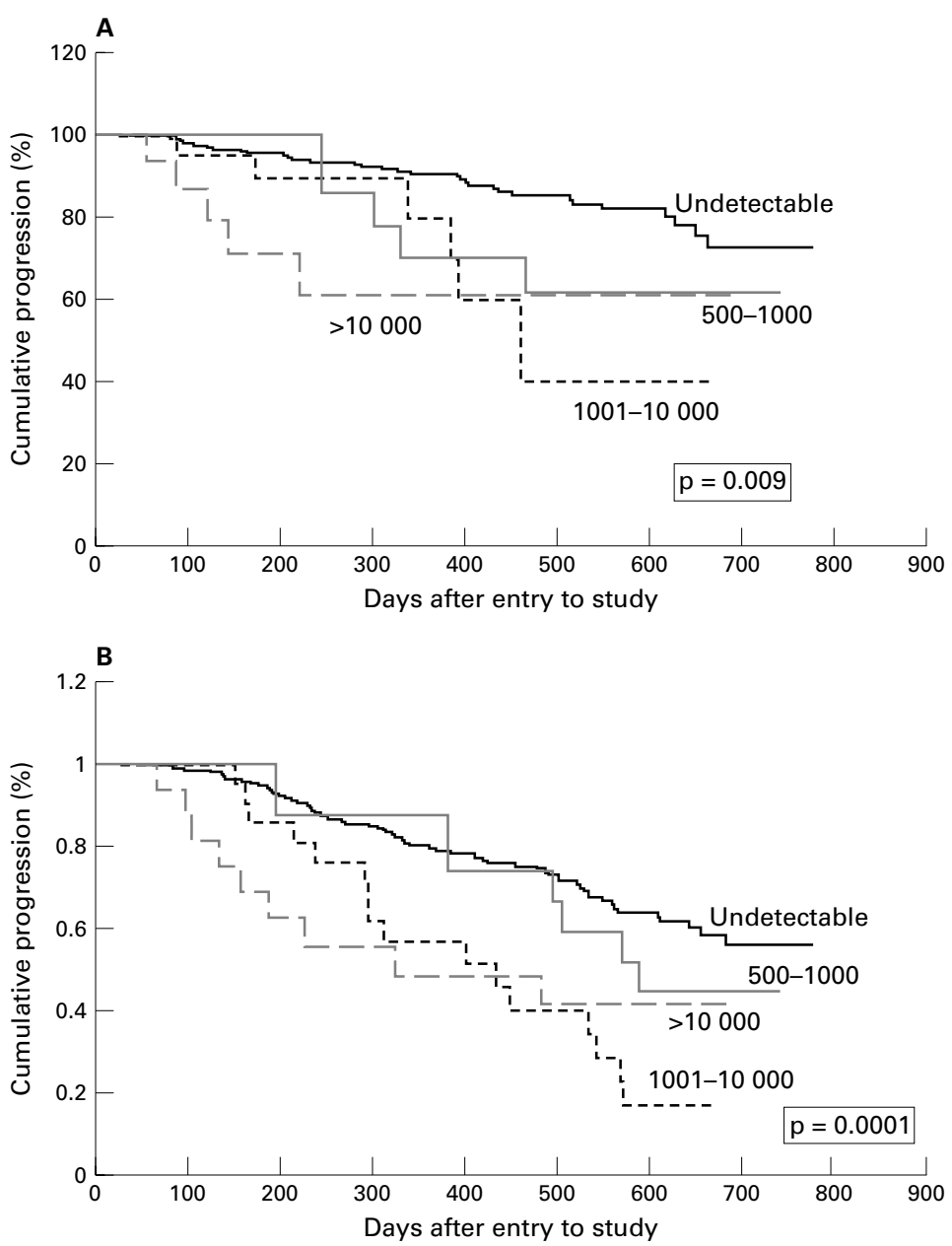

Figure 2 Kaplan-Meier survival curves showing the influence of baseline cytomegalovirus $(C M V)$ load in the blood on $(A)$ time to disease and $(B)$ death in a cohort of human immunodeficiency virus (HIV) infected individuals enrolled in ACTG204. ${ }^{58}$ globulin (ATG) is wholly explained by raised CMV load..$^{53}$ The molecular pathological mechanisms for this effect have not been defined but, whereas ATG is a selective anti-T cell agent, methylprednisolone acts as a broad immune suppressive agent, affecting both $\mathrm{T}$ cells and monocyte/macrophage differentiation. Therefore, at the level of tissue pathology, abrogation of functional tissue macrophages may be an important factor in CMV disease development. Recently, we have extended these studies to show that the rate of increase and quantity of viral load during the earliest stages of replication can be used to predict whether patients will go on to develop CMV related pathology. ${ }^{54}$

In HIV positive individuals, CMV load in whole blood and plasma have also been shown to be important predictors of pathogenesis. ${ }^{46-48} 55$ The presence of CMV DNA in the blood of HIV positive patients identifies a group of patients who are almost 20 times more likely to progress to CMV disease than those who remain negative for CMV DNA in the blood. ${ }^{465}$ In addition, an increasing CMV load in the blood was associated with an increased risk for disease progression. ${ }^{55}$ Bowen et al in 1996 provided the first data showing that CMV load was associated with a shorter time to progression and to death. ${ }^{48}$ Subsequently, the availability of data from large cohorts participating in prophylactic trials of anti-CMV drugs, such as ganciclovir and valaciclovir, has verified these initial studies. ${ }^{56-58}$ A typical Kaplan-Meier survival curve for progression to death according to baseline CMV load is shown in fig $2 .^{58}$ Indeed, recent analysis of the ganciclovir 1654 study has shown that the effect of CMV load at the initiation of drug treatment (some considerable time period before patients exhibit CMV disease) has more effect on survival than does HIV RNA load. ${ }^{59}$

\section{Conclusions}

The availability of modern molecular methods has facilitated the study of CMV in vivo. The results demonstrate that CMV load is crucial in the pathogenic process and provide new insights into optimal drug regimens and duration of treatment. Obviously, the pathological processes that are responsible for the risk of CMV disease, and the variation between different immunocompromised hosts, require delineation. However, our improved understanding of CMV replication in vivo is likely to impact on patient management and the deployment of existing and newer therapeutic agents in the near future.

I am grateful to my colleagues and collaborators for allowing me to cite their data in this review. Work in my laboratory is supported financially by the Medical Research Council, the National Institutes of Health USA, and the Wellcome Trust.

1 Griffiths PD, Emery VC, eds. Cytomegalovirus. In: Richman DD, Whitley RJ, Hayden FG. Clinical virology. New York: Churchill Livingstone, 1997:445-70.

2 Mocarski ESJ. Cytomegalovirus biology and replication. In: Roizman B, Whitley RJ, Lopez C, eds. The human herpesviruses. New York: Raven Press, 1993:173-226.

3 Chee MS, Bankier AT, Beck S, et al. Analysis of the proteincoding content of the sequence of human cytomegalovirus strain AD169. Curr Top Microbiol Immunol 1990;154:125-69.

4 Cha TA, Tom E, Kemble GW, et al. Human cytomegalovi-
rus clinical isolates carry at least 19 genes not found in rus clinical isolates carry at least 19 gen
laboratory strains. $\mathcal{F}$ Virol 1996;70:78-83. 
5 Chou S. Comparative analysis of sequence variation in gp 116 and gp55 components of glycoprotein B of human cytomegalovirus. Virology 1992;188:388-90.

6 Chou SW. Reactivation and recombination of multiple cytomegalovirus strains from individual organ donors. $\mathcal{F}$ Infect Dis 1989;160:11-15.

7 Chou SW, Dennison KM. Analysis of interstrain variation in cytomegalovirus glycoprotein B sequences encoding neutralization-related epitopes. F Infect Dis 1991;163:1229 34.

8 Soderberg-Naucler C, Fish KN, Nelson JA. Reactivation of latent human cytomegalovirus by allogeneic stimulation of latent human cytomegalovirus by allogeneic stimulation
blood cells from healthy donors. Cell 1997;91:119-26.

9 Ho DD, Neumann AU, Perelson AS, et al. Rapid turnover of plasma virions and CD4 lymphocytes in HIV-1 infection. Nature 1995;373:123-6.

10 Wei X, Ghosh SK, Taylor ME, et al. Viral dynamics in human immunodeficiency virus type 1 infection. Nature 1995;373:117-22

11 Nowak MA, Bonhoeffer S, Hill AM, et al. Viral dynamics in hepatitis B virus infection. Proc Natl Acad Sci US A 1996; 93:4398-402.

12 Neumann AU, Lam NP, Dahari H, et al. Hepatitis C viral dynamics in vivo and the antiviral efficacy of interferondynamics in vivo and the antiviral eff
alpha therapy. Science 1998;282:103-7.

13 Emery VC, Cope AV, Bowen EF, et al. The dynamics of human cytomegalovirus replication in vivo. $\mathcal{f} \operatorname{Exp} \mathrm{Med}$ 1999;190:177-82.

14 Wagner B, Kropff B, Kalbacher $\mathrm{H}$, et al. A continuous sequence of more than 70 amino acids is essential for antibody binding to the dominant antigenic site of glycoprotein gp58 of human cytomegalovirus. F Virol 1992;66:5290-7.

15 Ohlin M, Sundqvist VA, Mach M, et al. Fine specificity of the human immune response to the major neutralization the human immune response to the major neutralization epitopes expressed on cytomegalovirus gp $58 / 116$ (gB), as
determined with human monoclonal antibodies. F Virol determined with

16 Wills MR, Carmichael AJ, Mynard K, et al. The human cytotoxic T-lymphocyte (CTL) response to cytomegalovirus is dominated by structural protein pp65: frequency, specificity, and T-cell receptor usage of pp65-specific CTL. f Virol 1996;70:7569-79.

17 McLaughlin-Taylor E, Pande H, Forman SJ, et al. Identification of the major late human cytomegalovirus matrix protein pp65 as a target antigen for CD8+ virus-specific cytotoxic T lymphocytes. 7 Med Virol virus-specific cytot

18 Emery VC. Tuning to the right frequency: cytotoxic T lymphocytes and cytomegalovirus. Transplantation 2000;69: 2241-2.

19 Engstrand M, Tournay C, Peyrat MA, et al. Characterization of CMVpp65-specific CD8+ T lymphocytes using MHC tetramers in kidney transplant patients and healthy participants. Transplantation 2000;69:2243-50.

20 Singhal S, Shaw JC, Ainsworth J, et al. Direct visualization and quantitation of cytomegalovirus-specific CD8+ cytotoxic T-lymphocytes in liver transplant patients. Transplantation 2000;69:2251-9.

21 Ploegh HL. Viral strategies of immune evasion. Science 1998;280:248-53.

22 Gilbert MJ, Riddell SR, Plachter B, et al. Cytomegalovirus selectively blocks antigen processing and presentation of its immediate-early gene product. Nature 1996;383:720-2.

23 Borrego F, Ulbrecht $\mathrm{M}$, Weiss EH, et al. Recognition of human histocompatibility leukocyte antigen (HLA)-E complexed with HLA class I signal sequence-derived peptides by CD94/NKG2 confers protection from natura
killer cell-mediated lysis. $\mathscr{f}$ Exp Med 1998;187:813-18.

24 Hassan-Walker AF, Cope AV, Griffiths PD, et al. Transcription of the human cytomegalovirus natural killer decoy gen

25 Browne H, Churcher M, Minson T. Construction and characterization of a human cytomegalovirus mutant with the 6784-7.

26 Browne H, Smith G, Beck S, et al. A complex between the MHC class I homologue encoded by human cytomegalovirus and beta 2 microglobulin. Nature 1990;347:770-2

27 Reyburn HT, Mandelboim O, Vales-Gomez M, et al. The class I MHC homologue of human cytomegalovirus inhibits attack by natural killer cells. Nature 1997;386:514-17.

28 Bodaghi B, Jones TR, Zipeto D, et al. Chemokine sequestration by viral chemoreceptors as a novel viral escape strategy: withdrawal of chemokines from the environment of cytomegalovirus-infected cells. F Exp Med 1998;188:855-66.

29 Pleskoff O, Treboute C, Brelot A, et al. Identification of a chemokine receptor encoded by human cytomegalovirus as chemokine receptor encoded by human cytomegalovi

30 Penfold ME, Dairaghi DJ, Duke GM, et al. Cytomegalovirus encodes a potent alpha chemokine. Proc Natl Acad Sci U S A 1999;96:9839-4 .

31 Pillay D, Emery VC, Griffiths PD. Clinical aspects of treatment of cytomegalovirus. In: Jeffries DJ, DeClercq E, eds. Antiviral chemotherapy. New York: Wiley, 1995:265-83.

32 Emery VC. Cytomegalovirus drug resistance. Antiviral Therapy 1998;3:239-42.

33 Grundy JE, Shanley JD, Griffiths PD. Is cytomegalovirus interstitial pneumonitis in transplant recipients an immunopathological condition? Lancet 1987;2:996-9.

34 Millar AB, Patou G, Miller RF, et al. Cytomegalovirus in the lungs of patients with AIDS. Respiratory pathogen or passenger? Am Rev Respir Dis 1990;141:1474-7.
35 Squire SB, Lipman MC, Bagdades EK, et al. Severe cytomegalovirus pneumonitis in HIV infected patients with higher than average CD4 counts. Thorax 1992:47:301-4.

36 Karavellas MP, Lowder CY, Macdonald C, et al. Immune recovery vitritis associated with inactive cytomegalovirus retinitis: a new syndrome. Arch Ophthalmol 1998;116:16975 .

37 Karavellas MP, Plummer DJ, Macdonald JC, et al. Incidence of immune recovery vitritis in cytomegalovirus retinitis patients following institution of successful highly active antiretroviral therapy. F Infect Dis 1999;179:697-700.

38 Ljungman P, Plotkin SA. Workshop of CMV disease: definitions, clinical severity scores, and new syndromes. Scand 7 Infect Dis Suppl 1995;99:87-9.

39 Mattes FM, McLaughlin JE, Emery VC, et al. Histopathological detection of owl's eye inclusions is still specific for cytomegalovirus in the era of human herpesviruses 6 and 7 . f Clin Pathol 2000;53:612-14.

40 Mellors JW, Kingsley LA, Rinaldo CR, Jr, et al. Quantitation of HIV-1 RNA in plasma predicts outcome after seroconversion. Ann Intern Med 1995;122:573-9.

41 Lau JY, Davis GL, Kniffen J, et al. Significance of serum hepatitis C virus RNA levels in chronic hepatitis C. Lancet 1993;341:1501-4.

42 Stagno S, Reynolds DW, Tsiantos A, et al. Comparative serial virologic and serologic studies of symptomatic and subclinical congenitally and natally acquired cytomegalovirus infections. F Infect Dis 1975;132:568-77.

43 Spector SA, Merrill R, Wolf D, et al. Detection of human cytomegalovirus in plasma of AIDS patients during acute visceral disease by DNA amplification. 7 Clin Microbiol 1992;30:2359-65.

44 Saltzman RL, Quirk MR, Jordan MC. High levels of circulating cytomegalovirus DNA reflect visceral organ disease in viremic immunosuppressed patients other than marrow recipients. F Clin Invest 1992;90:1832-8.

45 Kuhn JE, Wendland T, Schafer P, et al. Monitoring of renal allograft recipients by quantitation of human cytomegalovirus genomes in peripheral blood leukocytes. F Med Virol 1994;44:398-405.

46 Bowen EF, Sabin CA, Wilson P, et al. Cytomegalovirus (CMV) viraemia detected by polymerase chain reaction identifies a group of HIV-positive patients at high risk of CMV disease. AIDS 1997;11:889-93.

47 Bowen EF, Emery VC, Wilson P, et al. CMV PCR viraemia in patients receiving ganciclovir maintenance therapy for retinitis: correlation with disease in other organs, progression of retinitis and appearance of resistance. AIDS 1998;12:605-11.

48 Bowen EF, Wilson P, Cope A, et al. Cytomegalovirus retinitis in AIDS patients: influence of cytomegaloviral load on response to ganciclovir, time to recurrence and survival. AIDS 1996;10:1515-20.

49 Cope AV, Sabin C, Burroughs A, et al. Interrelationships among quantity of human cytomegalovirus (HCMV) DNA in blood, donor-recipient serostatus, and administration of methylprednisolone as risk factors for HCMV disease following liver transplantation. F Infect Dis 1997;176:148490 .

50 Cope AV, Sweny P, Sabin C, et al. Quantity of cytomegalovirus viruria is a major risk factor for cytomegalovirus diseas after renal transplantation. $\mathcal{F}$ Med Virol 1997;52:200-5.

51 Fox JC, Kidd IM, Griffiths PD, et al. Longitudinal analysis of cytomegalovirus load in renal transplant recipients using a quantitative polymerase chain reaction: correlation with disease. F Gen Virol 1995;76:309-19.

52 Gor D, Sabin C, Prentice HG, et al. Longitudinal fluctuations between peak virus load, donor/recipient serostatus, acute GvHD and CMV disease. Bone Marrow Transplant 1998;21:597-605.

53 Hassan-Walker AF, Kidd IM, Sabin C, et al. Quantity of human cytomegalovirus (CMV) DNAemia as a risk factor for CMV disease in renal allograft recipients: relationship with donor/recipient CMV serostatus, receipt of aug-
mented methylprednisolone and anti-thymocyte globulin (ATG). F Med Virol 1999;58:182-7.

54 Emery VC, Sabin CA, Cope AV, et al. Application of viral-load kinetics to identify patients who develop cytomegalovirus disease after transplantation. Lancet 2000;355: 2032-6.

55 Shinkai M, Bozzette SA, Powderly W, et al. Utility of urine and leukocyte cultures and plasma DNA polymerase chain reaction for identification of AIDS patients at risk for developing human cytomegalovirus disease. 7 Infect Dis 1997;175:302-8.

56 Spector SA, Wong R, Hsia K, et al. Plasma cytomegalovirus (CMV) DNA load predicts CMV disease and survival in (CMV) DNA load predicts CMV disease and

57 Griffiths PD, Feinberg J, Fry J, et al. The effect of valaciclovir on cytomegalovirus viremia and viruria detected by polymerase chain reaction in patients with advanced human immunodeficiency virus disease. $\mathcal{F}$ Infect Dis 1998;177:57-64.

58 Emery VC, Sabin C, Feinberg JE, et al. Quantitative effects of valaciclovir on the replication of cytomegalovirus in patients with advanced human immunodeficiency virus disease: baseline cytomegalovirus load dictates time to disease and survival. F Infect Dis 1999;180:695-701.

59 Spector SA, Hsia K, Crager M, et al. Cytomegalovirus (CMV) DNA load is an independent predictor of CMV disease and surival in advanced AIDS. F Virol 1999;73: 7027-30. 